\title{
Pax2, a new murine paired-box-containing gene and its expression in the developing excretory system
}

\author{
GREGORY R. DRESSLER*, URBAN DEUTSCH, KAMAL CHOWDHURY, HOWARD O. NORNES $\dagger$ \\ and PETER GRUSS $\$$ \\ Department of Molecular Cell Biology, Max Planck Institute for Biophysical Chemistry, 3400 Goettingen, FRG \\ * Present address: Laboratory of Molecular Genetics, National Institute of Child Health and Human Development, National Institute of \\ Health, Bethesda, Maryland 20892, USA \\ +On leave from the Department of Anatomy and Neurobiology, Colorado State University, Fort Collins, Colorado 80523, USA \\ $\ddagger$ Corresponding author
}

\section{Summary}

The murine genome contains multiple genes with protein domains homologous to the Drosophila paired box, present in certain segmentation genes. At least one of these murine paired box (Pax) genes is associated with a developmental mutation. This report, in conjunction with the accompanying paper, describes a second member of this gene family, $P a x 2$, that is also expressed during embryogenesis. Two overlapping cDNA clones were isolated and sequenced. At least two forms of the $\operatorname{Pax} 2$ protein can be deduced from the cDNA sequence. In addition to the highly conserved paired domain, an octapeptide sequence is located downstream. Expression of $\operatorname{Pax} 2$ is primarily restricted to the developing embryo in the excretory and central nervous systems. The transient nature of Pax 2 expression during kidney organogenesis correlates with polarization and induction of epithelial structures and may indicate an important morphogenetic role for this gene.

Key words: paired box, Pax, kidney development, mouse embryology.

\section{Introduction}

The identification and characterization of Drosophila developmental mutations has helped to elucidate the morphogenetic mechanisms of embryonic segmentation and pattern formation (for reviews see Ingham, 1988; Akam, 1987; Scott and Carroll, 1987). As an approach to address genetic aspects of vertebrate development, three different mouse gene families have been identified based on sequence similarities to certain Drosophila homeotic and segmentation genes (for review see Dressler and Gruss, 1988). The conservation of protein domains among such highly divergent species suggests a similarity of biochemical function that may control common morphological processes, or alternatively, may be adapted to more unique species-specific events. Many vertebrate genes, with domains homologous to the Drosophila Antp-type homeobox, have been identified and much of the available evidence suggests a developmental role for these genes (for reviews see Wright et al. 1989; Holland and Hogan, 1988).

A second conserved protein domain, termed the paired box, was discovered among the Drosophila segmentation genes paired (prd), gooseberry-proximal (gsb-p), and gooseberry-distal (gsb-d) (Bopp et al. 1986). The mouse genome also contains multiple paired-box-containing genes, called $\mathrm{Pax}$ genes (Dressler et al. 1988). A member of this gene family that is expressed in segmented structures of the developing vertebral column was recently described (Deutsch et al. 1988). Furthermore, there is sufficient evidence to suggest that this gene, $\operatorname{Pax} 1$, is the mouse developmental mutation undulated (Balling et al. 1988). In undulated mice, vertebral malformations occur presumably because sclerotome cells either do not migrate and resegment properly in their respective halves or the differentiation of sclerotome cells into prevertebrae and intervertebral disk anlagen is affected (Grüneberg, 1954). Clearly, the evidence indicates that a mutation in the paired box disrupts a specific morphogenetic event during mouse development.

Since the mouse genome contains multiple copies of the paired box, it is of interest to characterize other members of the Pax gene family and determine if they also are involved in developmental processes. This 
report, in conjuction with the accompanying paper (Nornes et al. 1990), describes the identification, primary structure and developmental expression of Pax2.

\section{Materials and methods}

\section{Screening of mouse cDNA libraries}

After transfer to Hybond-N filters (Amersham), $8 \times 10^{5}$ clones of a 12.5 days p.c. embryonic mouse $\lambda g t 10$ cDNA library (Joyner and Martin, 1987) were hybridized under low-stringency conditions $\left(7 \times \mathrm{SSC}, 60^{\circ} \mathrm{C}\right)$ with a $313 \mathrm{bp} \mathrm{HinclI}-\mathrm{SacI}$ Paxl paired-box probe, labeled by random priming (Feinberg and Vogelstein, 1983). The filters were washed three times in $2 \times \operatorname{SSC} / 0.2 \%$ SDS at $42^{\circ} \mathrm{C}$. The cDNA clone c $31 \mathrm{~A}$ was isolated by standard techniques.

The cDNA clone cPX was isolated from a 8.5 days p.c. embryonic mouse $\lambda \mathrm{gt} 10$ cDNA library (Fahrner et al. 1987) in a low-stringency screen using a mixture of Paxl (313 bp HinclI-Sacl fragment), Pax2 (574 bp Notl-BamHI fragment), and $\operatorname{Pax} 3$ (Deutsch, unpublished) paired-box probes as described above.

\section{DNA sequencing}

The cDNA inserts were cloned into the plasmid vector Bluescript (Stratagene Inc.) and mapped with various restriction enzymes. Subfragments were cloned into M13 and sequenced with the dideoxy method (Sanger et al. 1977). The GC rich EcoRI-NotI fragment, spanning nucleotides 1-295, was also sequenced with the method of Maxam and Gilbert (1980).

\section{RNA isolation from mouse tissue and embryos}

Female NMRI outbred mice were mated overnight and the day of the vaginal plug was noted as day 0 . Embryos were dissected free of extraembryonic tissue and frozen in liquid nitrogen. RNA was isolated by homogenizing tissues and embryos in guanidinium thiocyanate (Chirgwin et al. 1979) and centrifugation through a $5.7 \mathrm{~m} \mathrm{CsCl}, 25 \mathrm{~mm}$ sodium acetate $\mathrm{pH} 5.0$ cushion in a Beckman SW41 rotor spun at $31000 \mathrm{rev} \mathrm{min}^{-1}$ for $22 \mathrm{~h}$. Poly(A) ${ }^{+}$RNAs were obtained by retention on oligo(dT)-cellulose columns. Approximately $5 \mu \mathrm{g}$ of the respective RNAs were electrophoresed through a $1 \%$ agarose, $3.7 \%$ formaldehyde gel in $20 \mathrm{~mm}$ MOPS (morpholine propane sulfonic acid) buffer. The RNA was blotted onto gene screen plus membranes (New England Nuclear) and hybridized with the $527 \mathrm{bp} B a m \mathrm{HI}-E c o \mathrm{RI}$ fragment of $c 31 \mathrm{~A}$. The probe was labeled with the random prime method of Feinberg and Vogelstein (1983). The membranes were washed twice in $2 \times \mathrm{SSC}, 1 \%$ SDS at $65^{\circ} \mathrm{C}$ and twice in $0.1 \times \mathrm{SSC}, 1 \% \mathrm{SDS}$ at $65^{\circ} \mathrm{C}$.

\section{In situ hybridization}

The $527 \mathrm{bp} \mathrm{BamHI-EcoRI} \mathrm{fragments} \mathrm{from} \mathrm{clone} \mathrm{c31A} \mathrm{was}$ subcloned into the Bluescript vector (Stratagene) and the resulting plasmid was linearized with restriction endonuclease. Single-stranded RNA probes were transcribed in vitro using $100 \mu \mathrm{Ci}{ }^{35} \mathrm{~S}$-UTP and T3 or T7 polymerases (Promega Biotech.). After DNAse digestion, probes were precipitated with $10 \%$ trichloroacetic acid and collected on nitrocellulose filters (Millipore). Probes were eluted from the filters in $20 \mathrm{~mm}$ EDTA pH 8.0, $0.1 \% \mathrm{SDS}$ at $65^{\circ} \mathrm{C}$. Following ethanol precipitation, probes were partially degraded with $0.2 \mathrm{~N}$ $\mathrm{NaOH}$ on ice for $30-60 \mathrm{~min}$ and neutralized with $1 \mathrm{M}$ acetic acid. After ethanol precipitation, the probes were resuspended in $50 \%$ formamide, $10 \mathrm{~mm}$ DTT.
Sections were prepared and hybridized essentially as described by Hogan et al. (1986) with modifications by Dony and Gruss (1987). Sections were cut in a cryostat and transferred onto subbed slides. The sections were dried at $55^{\circ} \mathrm{C}$, fixed in $4 \%$ paraformaldehyde (PFA) and dehydrated in graded ethanol. Slides were kept at $-20^{\circ} \mathrm{C}$ until the day of hybridization. Slides were dipped in phosphate-buffered saline (PBS) and incubated at $70^{\circ} \mathrm{C}$ in $2 \times S S C$ (standard saline citrate). After a second PBS rinse, slides were digested with $0.125 \mathrm{mg} \mathrm{ml}^{-1}$ pronase for $10 \mathrm{~min}$ at room temperature and the digestion was stopped in $0.2 \%$ glycine for $30 \mathrm{sec}$. Slides were rinsed in PBS and refixed in $4 \%$ PFA for $20 \mathrm{~min}$ and rinsed again in PBS. Slides were acetylated in $0.1 \mathrm{M}$ triethanolamine with $1 / 400$ volume acetic anhydride, made fresh. Slides were rinsed again in PBS and dehydrated in graded ethanol. After prolonged air drying, the hybridization mixture was added. The probe was diluted to approximately $5 \times 10^{4} \mathrm{cts} \mathrm{min}^{-1} \mu \mathrm{l}^{-1}$ in a buffer containing $50 \%$ formamide, $0.3 \mathrm{M} \mathrm{NaCl}, 10 \mathrm{~mm}$ Tris, $10 \mathrm{~mm} \mathrm{NaPO}$ (pH 6.8), $5 \mathrm{~mm}$ EDTA, $1 \times$ Denhardts, $10 \%$ dextran sulphate, $10 \mathrm{~mm}$ DTT, and $1 \mathrm{mg} \mathrm{ml}^{-1}$ tRNA. The hybridization mix was boiled for $2 \mathrm{~min}$, applied directly onto sections and covered with a siliconized cover slip. Hybridzation was done overnight in a humid chamber at $50^{\circ} \mathrm{C}$. Washing was done for $3-4 \mathrm{~h}$ in $50 \%$ formamide, $2 \times \mathrm{SSC}$ at $37^{\circ} \mathrm{C}$ followed by RNAse digestion (Ingham et al. 1985). A second wash in $50 \%$ formamide, $2 \times$ SSC was done overnight and the slides were then dehydrated in graded ethanol.

Slides were dipped in Kodak NTB-2 emulsion diluted 1:1 with water and allowed to dry in a dark chamber for $2-3 \mathrm{~h}$. Slides were placed in a dark plastic box, wrapped in foil, and allowed to expose for 6-10 days. Development was done at room temperature for $3 \mathrm{~min}$ in Kodak D-19, followed by $30 \mathrm{~s}$ in $1 \%$ acetic acid and $3 \mathrm{~min}$ in $30 \%$ sodium thiosulphate. After repeated washes in distilled water, the slides were stained with Giemsa and allowed to dry. Photomicrographs were taken with a Leitz Labovert bright-field/dark-field microscope.

\section{Results}

\section{Structure of the Pax2 cDNAs}

The two partially overlapping cDNA clones, corresponding to the mouse $\operatorname{Pax} 2 \mathrm{mRNA}$, are outlined in Fig. 1. The clone $\mathrm{c} 31 \mathrm{~A}$ was isolated from a 12 day embryonic cDNA library using the mouse Paxl paired box as a probe, under low-stringency conditions. Sub-

5.
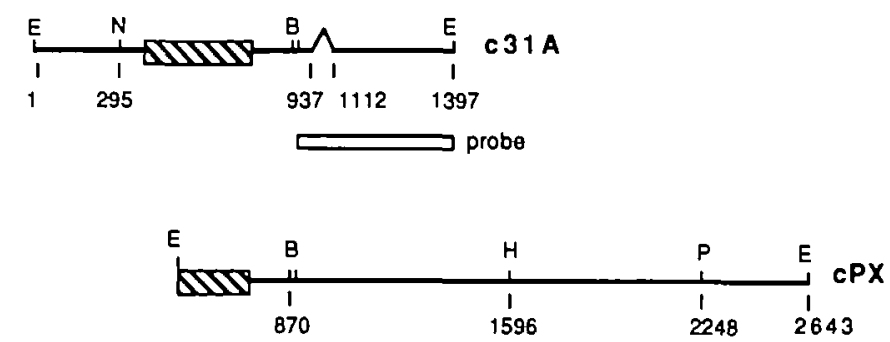

Fig. 1. The structure of Pax 2 cDNAs. The two overlapping Pax2 cDNAs are outlined. The paired domain is indicated by a hatched box. The probe used for in situ hybridization is indicated by an open box. Restriction sites are: B,

BamHI; E, EcoRI; H, HindIII; N, NotI; P, Pstl. 
sequently, an 8.5 day embryonic cDNA library was screened with a mixture of three murine paired box probes under low-stringency and one additional Pax2 cDNA clone, cPX, was identified upon further DNA sequencing. Together, the two cDNAs span $2623 \mathrm{bp}$ of the Pax 2 mRNA. The complete nucleotide sequence of the two overlapping cDNA clones is shown in Fig. 2.

The clone $\mathrm{c} 31 \mathrm{~A}$ does not have a poly $(\mathrm{A})^{+}$tract at its $3^{\prime}$ end and, thus, may be the result of an internal cleavage during the construction of the library. The clone cPX does contain a stretch of 15 adenosine residues at the $3^{\prime}$ end; however, no AAUAAA polyadenylation signal (Proudfoot and Brownlee, 1976;
Fitzgerald and Shenk, 1981) is present. Thus, it is unlikely that clone cPX represents the true $3^{\prime}$ end of the Pax2 mRNAs. A comparison of the overlapping region between c31A and $\mathrm{cPX}$ revealed a gap of 69 nucleotides in clone c31A between position 937 and 1005. Otherwise, the two cDNA clones are completely colinear. It is likely that this deletion represents an alternative splicing pathway during $\operatorname{Pax} 2$ mRNA maturation. Interestingly, this small deletion does not change the reading frame of the coding sequence.

\section{The Pax 2 protein}

The overlapping Pax2 cDNAs encode an open reading
1 GGAATTCCGGCAGGCGCGCGCCGCGGCGACCGAAGGGCCCCTTGGTCCAGCCAGTCGCCCCGGGGCTGCGTTGCTGACTGCCCAGCCGCG

91 TGCCCCAACGGTGGCAAGTTGCAGCCTCTGCGGTCGCAAACCCCAGCGGGCCCGGAGGAGTCCCGGCGTGGAGCGCGGCGCGGCGTCCCC

181 CGCCCTCGCTTGCCCCCCAGCAGTCGGGCGCCCGCTCACTCTCCCTCCCCCACCGTCCCTTCCTTTTCTCCTCAAGTCCTGAAGTTGAG

90

180
270

271

TTGAGAGGCGACACGGCGGCGGCGGCCGCGTTGCTCCCGCTCCTCTGCCTCCCGATGGATATGCACTGCAAAGCAGACCCCTTCTCCGCG MetAspMetHisCy $\mathbf{s}$ SAlaAspP roPheSerAla

ATGCACCGGCACGGGGGTGTGAACCAGCTCGGGGGGGTGTTTGTGAACGGCCGGCCCCTACCCGACGTGGTGAGGCAGCGCATCGTGGAG MetH1sArgH1sGlyGlyValAsnGlnLeuGlyGlyVal PheValAsnglyArgP roLeuProAspValValArgGlnArgI leValGlu CTGGCCCACCAGGGTGTGCGGCCCTGTGACATCTCCCGGCAGCTGCGGGTCAGCCATGGCTGTGTCAGCAAAATCCTGGGCAGGTACTAC

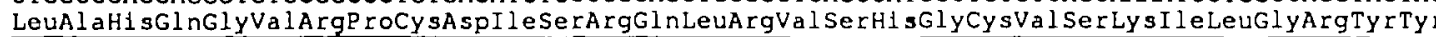

541 GAGACTGGCAGCATCAAGCCCGGAGTGATTGGTGGCTCCAAGCCCAAGGTGGCAACGCCCAAAGTGGTGGACAAGATTGCCGAATACAAG GluThrGlySerI leLysP roGlyValI leGlyGlySerLysProLysValAlaThrProLysValValAspLysI leAlaGluTyrLys

631 CGACAGAACCCGACTATGTTCGCCTGGGAGATCCGTGCACAGCTGCTACGCGAGGGCATCTGCGATAATGACACAGTTCCCAGTGTCTCA ArgGlnAsnP roThrMetPheAlatrpGluI leArgAlaGl nLeuLeuArgGIUGly I eCy sAspAsnAspThrValProSerVal Ser TCCATCAACAGGATCATCCGGACCAAAGTTCAGCAGCCTTTCCACCCAACGCCGGATGGGGCAGGGACAGGAGTGACTGCCCCCGGCCAC SerI leAsnArgI leI leArgThrLysValGlnglnProPheHI sProThrProAspGlyAlaGlyThrGlyValThralaProGlyHis

ACCATCGTTCCCAGCACGGCCTCCCCTCCTGTTTCCAGCGCCTCTAACGACCCAGTGGGATCCTACTCCATCAACGGGATCCTGGGGATT

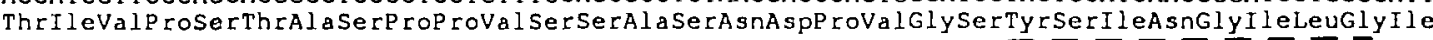
CCTCGCTCCAACGGTGAGAAGAGGAAACGCGAGGAAGTCGAGGTATACACTGATCCTGCCCACATTAGAGGAGGTGGAGGTTTACATCTG

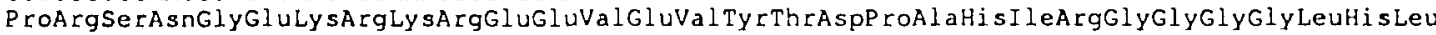
GTCTGGACTTTAAGAGATGTGTCTGAGGGCTCTGTCCCTAATGGAGACTCCCAGAGTGGTGTGGACAGTT TGCGGAAGCACCTGCGAGCC Val TrpThrLeuArgAspVal SerGluGl y SerValProAsnglyAspSerGinSerGlyValAspSerLeuArgLysHis LeuArgAla GACACCTTCACCCAGCAGCAGCTGGAAGCTCTGGATCGAGTCTTTGAGCGTCCTTCCTATCCCGATGTCTTCCAGGCATCAGAGCACATC AspThrPheTh rGl IGInGl nLeuGluAl a LeuA SPA rgValPheGluArgP roSerTy AAATCAGAACAGGGGAATGAATACTCTCTCCCAGCCCTGACCCCTGGGCT TGATGAAGTCAAGTCCAGTCTATCTGCATCGGCCAACCCT Lys SerGluGlnGlyA sngluTy SSerLeuP roAla LeuThrP roGly LeuAspgluVal Lys SerSerLeuSerAlaSerAlaAsnPro GAGCTGGGCAGCAATGTGTCAGGCACACAGACGTACCCCGTTGTGACCGGTCGTGATATGACGAGCACCACTCTACCTGGTTACCCCCCG GluLeugly SerAsnValSerGlyThrGInThrTy rProValValThrGlyArgAspmetThrSerThrThrLeuProGlyTyrProPro CATTTGCCCCCCACTGGCCAGGGAAGCTACCCTACCTCCACCCTGGCAGGAATGGTGCCTGGGAGCGAGT TCTCAGGCAACCCATACAGC His LeuP coProThrGlyGlnglySerTy rP roThrSerThrLeuAlaglyMetValProglySerGluPheSerGlyAsnProTyrSer CATCCCCAGTACACCGCCTACAATGAGGCTTGGAGATTCAGCAACCCCGCCTTACTAAGTTCCCCTTATTATTATAGTGCCGCCCCCCGG Hi sProGl nTy ThrAla Ty rASnGluAla TrPArgPheSerAsnProAlaLeuLeuSerSerProTyrTyrTyrSerAlaAlaProArg TCCGCCCCTGCCGCTCGTGCCGCTGCCTATGACCGCCACTAGTTACCGCGGGGACCACATCAAGCTTCAGGCAGACAGCTTCGGCCTCCA

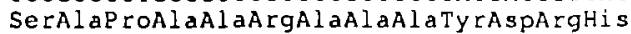

CATCGTCCCCGTCTGACCGCCCACCCCAGAGGGAGGGAGGACCGAAGCGACGCCGTGCCTCTCGGCCACCGTCCCTGTCCCACCCCCACC TCGAGACATCCTCCCCCAAGCCCCGCAGCCCTTCTCATCACCCTGTCGATGGCCAGACAGGACAGGTGGAGCCGCGGGTGGGACCCTCAG GCCCCAGCCCCGCCCGTCGCCCCTCCCCGCCTGCCTGGACCGCGGCGCCGTCCGGAAGCCCGCCCGCCTCTGGCCCGCGCGCCGTTTCTO TGACACACAATCAGCGTGGCCCACCCAGGGGCAGCCCACTTCGGACGCCCGGGAGTCGGAGGCTTCGCTGGAGAAGCTGAGCAAGGGAAG CTAAGGAAAGGACTTTGTGCTGAAGGAGGAGCCGCCGGGGAGACCTAGGGGGGAAATCCTGCCCCATCCCCCCTGTGCCTGCCAAGCTGA CCCCGCCTTCTGTCTGCGCCCCGCCCCAGACGGTGGCACTGGGACGCAAGGGTCGGACTCGAGGGACAGCGTT TGGGGCGACAGCGTTT T CCAAGGCTGGTACCCAAGGCGAGCAGACGCCAACTGAGCTCATCCACCTGAACTGCCTAGTTCCCTTGGGCCTGCGATCTCCTTCTGCAG TGACTCTCCTCTCGGCCCCGCCTTGCCCTTACGTCAGCGCCTCTTCCACCTGCTGGCCTCTCACTTTCCCTCCTGTGCTTCCTCGGCTCA TCCCACGACACCTTGTGTTTGGTCCCAAGCACGCAGCCACGTCGGGGCCACCGCGGGAACCGTGTCCTCAGGCTGCGGCTGCGAGCATTG ATCTTTCCCATCAGTAATGCGCTGCCCACCCCCACCCTCCCATCCCAAACTCCCAACCTGCGGGCGCAAAAAGCCTGGAAGGAACTGAC GACCGAGCCGCCCCAGATGAAAATCCGGGTCTCCCCGCCCCATTCCCCCCAAGCACCCCCTCCCCAGCCTTCCCTTGGCAGGAGCTGAAC AGAGCCTCAAAAAAAAAAAAAAA

Fig. 2. The DNA sequence and conceptual amino acid sequence of the Pax2 gene. The paired domain is indicated with a solid underline. The paired octapeptide is indicated with a dashed underline. The $5^{\prime}$ and $3^{\prime}$ borders of the 69 nuc. deletion in clone $\mathrm{c} 31 \mathrm{~A}$ are indicated with triangles. The predicted amino acid sequence starts at nucleotide 325 . Two additional potential translational start sites are located at nucleotides 331 and 361 . 


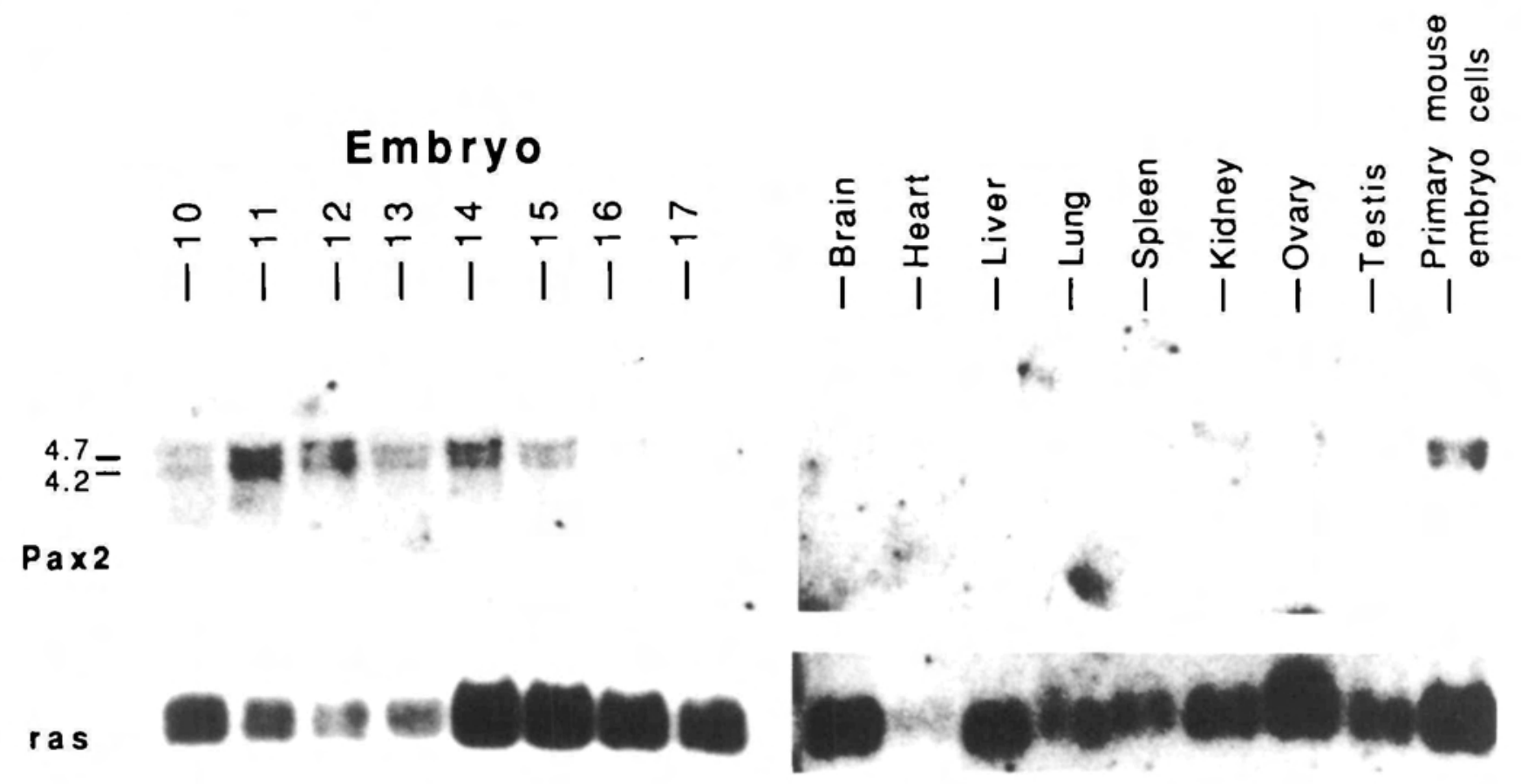

Fig. 3. Northern blot analysis of Pax 2 transcripts in embryos and adult tissues. Approximately $5 \mu \mathrm{g}$ of $\mathrm{A}+\mathrm{RNA}$ was hybridized with the Pax2-specific probe (indicated in Fig. 1) and a $c$-ras probe. For the Pax 2 probe, exposure times were 1 day for the embryonic RNAs and 7 days for the adult tissue RNAs.

frame of at least 415 amino acids that includes the paired box domain. The paired domain, as underlined in Fig. 2, begins with a histidine at amino acid position 14 and ends with a glutamine at position 144. This open reading frame continues until a stop codon is encountered at amino acid position 416 . The most $5^{\prime}$ methionine is encoded at nuc. 325 , with a second methionine codon at nuc. 331 and a third methionine codon at nuc. 361. At present, it has not been determined which of these potential AUGs serves as a translational start site. In addition, because the extremely GC-rich 5 ' leader sequence does not contain any upstream stop codons, it cannot be ruled out that the $N$-terminus of the $P a x 2$ protein lies further upstream in a region not represented on the cDNAs.

Comparison of the $\operatorname{Pax} 2$ paired domain to that of other paired domain proteins shows their high degree of homology. As evident in previous analyses of these sequences (Bopp et al. 1986; Deutsch et al. 1988; Burri et al. 1989), the paired domain consists of a more highly conserved $N$-terminal domain and less stringently conserved $C$-terminal domain. The first 74 amino acids of Pax2 are most homologous to the mouse gene Pax1 (Deutsch et al. 1988), the human gene HuP48 (Burri et al. 1989), and the Drosophila gene P29 (Burri et al. 1989). Overall, Pax2 is slightly more homologous to Pax 1, P29, and the human genes, with $69-72 \%$ amino acid identity, compared to the Drosophila prd and gsb genes, with $63-67 \%$ amino acid identity. A second homologous region among paired-domain proteins, termed the octapeptide, was recently noted by Burri et al. (1989). In Pax2, an octapeptide is found between amino acid positions 184-191. When compared to two human and two Drosophila sequences, six out of the eight amino acids match a consensus sequence and the only two substitutions also appear in one of the Drosophila gsb genes. There may be at least two variant forms of the Pax 2 protein. The clone c $31 \mathrm{~A}$ has spliced out a small 69 nuc. exon, spanning nuc. 937-1005 and present in the clone cPX. Thus, the corresponding mRNA would encode a $\operatorname{Pax} 2$ protein with a 23 amino acid deletion, as indicated in Fig. 2.

In a search for similarities to other known proteins, the NBRF protein sequence databank (Genetics Computer Group; Devereux et al. 1984) was screened with the complete $P a x 2$ sequence and the $P a x 2$ sequence minus the paired domain. The complete $\operatorname{Pax} 2$ protein is $22 \%$ identical, $41 \%$ similar, to human c-fos (van Straaten et al. 1983) and $22 \%$ identical, $40 \%$ similar, to mouse $c-m y c$ (Stanton et al. 1984), as determined by the BestFit sequence alignment program (Genetics Computer Group). Interestingly, the regions of similarity between Pax2 and $c$-fos and Pax2 and c-myc are different. These major sequence similarities are downstream of the paired domain.

\section{Transcripts of Pax2 are primarily restricted to embryogenesis}

In order to determine the spatial and temporal expression analysis of Pax2 in embryonic and adult tissues, Northern blotting and in situ hybridization was done with a $P a x 2$ specific probe downstream from the paired box sequence (see Fig. 1), to eliminate potential cross hybridization to other Pax genes. Initially, poly $(\mathrm{A})^{+}$selected RNA was isolated from embryos from day 10 to day 17 of gestation. Concurrently, 
poly $(\mathrm{A})^{+}$RNAs from various adult tissues were prepared. As demonstrated in Fig. 3, transcripts corresponding to the Pax2 gene can be detected during embryogenesis. Two transcripts are detected in embryonic poly $(\mathrm{A})^{+}$RNAs, approximately $4.2 \mathrm{~kb}$ and a $4.7 \mathrm{~kb}$ in size, that hybridize with a fragment from the Pax2 cDNA clone. Using $c$-ras transcripts (Leon et al. 1987) for standardization, the relative peak of Pax2 transcript accumulation occurs at approximately 11 days gestation and decreases thereafter. The two Pax 2 transcripts are expressed at near equimolar amounts in all positive samples tested. In adult tissues, Pax2 transcripts could not be detected in the brain, heart, liver, lung, spleen, ovary or testis, even after prolonged exposure of Northern blots (Fig. 3). In kidney RNA, a faint smear is visible after a prolonged 7 day exposure, although this appears somewhat larger than the embryonic transcripts. In addition, Pax2 mRNA could not be detected by in situ hybridization to adult kidneys or adult spinal chord (data not shown). Thus, $\mathrm{Pax} 2$ gene expression is primarily restricted to the developing embryo.

The tissue-specific developmental expression pattern of Pax 2 was examined by in situ hybridization to sections from mouse embryos, isolated at various developmental stages. The sections were hybridized with ${ }^{35} \mathrm{~S}$ UTP-labeled RNA probes corresponding to the sense and antisense strands of a unique $\operatorname{Pax} 2$ cDNA fragment. In addition, a mouse $H o x 3.1$ probe was used as a positive control (Breier et al. 1988). In mesodermderived tissues, Pax2 is expressed in the pronephric tubules and extending nephric duct beginning at day 9 . There is no detectable expression in mesoderm cells prior to extension of the Wolffian duct and formation of the pronephros. Representative micrographs are shown in Fig. 4 beginning at 10 days gestation. In the developing excretory system, $\operatorname{Pax} 2$ transcripts can be detected at 10 days p.c. in the nephric cord and Wolffian duct (Fig. 4A,B). At this time individual pronephric tubules express Pax2 transcripts, as seen in Fig. 4C,D. These segmented embryonic excretory organs are derived from the intermediate mesoderm, lateral to the somites (for a description and review of pro-, meso- and metanephric organogenesis see Saxen, 1987). However, no Pax2-specific hybridization is seen in mesoderm prior to formation of the nephric cord and Wolffian duct (data not shown).

The developing mesonephros also expresses $\mathrm{Pax} 2$ transcripts at 11 days gestation, as evident in Fig. 4E,F. At this time and more posterior to the mesonephros, the ureter has budded out from the Wolffian duct and has reached the metanephric mesenchyme to begin formation of the adult kidney. Part of the ureter is shown in Fig. 4G,H and it also hybridizes with the Pax2 probe, whereas the surrounding mesenchyme cells do not. Fig. 4I,J show a section through the first branching of the ureter and the condensation of metanephric mesenchyme cells around the branches. Both the branched ureter and the mesenchymal condensations express high levels of Pax 2 transcripts.

At 12 days gestation, the ureter has branched repeat- edly and sections through the metanephros reveal many early mesenchymal condensations around the developing collecting ducts. Pax2 is expressed in the collecting ducts as well as in the condensed mesenchyme cells (Fig. 4K,L). It is of interest to note the absence of $\mathrm{Pax} 2$ expression in non-condensed mesenchyme cells. This is demonstrated more clearly in Fig. 5. Cells of the metanephric mesenchyme that have not condensed around the branching collecting ducts do not appear to express Pax2 (Fig. 5A-D). At later developmental stages, Pax2 expression in the kidney declines (Fig. 5E-H). Although still actively expressed in the perimeter of the growing kidney at 14 and 17 days gestation, more mature renal tubules in the interior are expressing less Pax2-specific RNA. Thus, consistent with the Northern blotting data, expression of Pax2 declines and can no longer be detected by in situ hybridization in adult kidneys (data not shown).

\section{Discussion}

This report describes the isolation and characterization of a novel paired-box-containing gene, $P a x 2$, that is expressed during development. Using a mouse Paxl paired box probe (Deutsch et al. 1988), cDNA clones containing a related paired box and spanning $2623 \mathrm{bp}$ of Pax 2 mRNA sequence were isolated. These two overlapping cDNAs do not represent the complete Pax2 transcripts since Northern analysis reveals two mRNAs of approximately 4.2 and $4.7 \mathrm{~kb}$ in length. Whether the two Pax2 transcripts are generated by different transcription initiation sites, polyadenylation sites, or by an alternative splicing mechanism remains to be determined. In addition, it is unlikely that these two transcripts represent a kidney-specific and a neural tube specific mRNA because the relative molarity of the two transcripts remains constant during gestation while maximum levels of kidney expression and neural tube expression (Nornes et al. 1990) do not coincide precisely. An alternatively spliced mRNA was found among the cDNAs described; however, the extra 69 nuc. cannot account for the size difference seen between the two Pax2 transcripts. It is likely that multiple forms of the Pax2 mRNAs exist that can encode different forms of the paired domain protein.

At least two proteins, of 415 and 392 amino acids, could be encoded if translation starts at the most $5^{\prime}$ AUG of clone c31A. Because there are no stop codons $5^{\prime}$ to this AUG, the possibility that translation starts at an upstream AUG not present in the clone c31 A cannot be ruled out. However, several observations suggest either the first, second or third AUG, all located within a 36 nucleotide stretch, is the translation start site. The optimal sequence context for a eukaryotic translational start site, as determined by Kozak (1987a), is (GCC)GCC(A/G)CCAUGG. If a one nucleotide space is allowed for, $9 / 13$ nucleotides flanking the first methionine are identical to this consensus sequence. However, the sequence surrounding this first methionine has a $C$ at position -3 , where normally $A$ and $G$ 

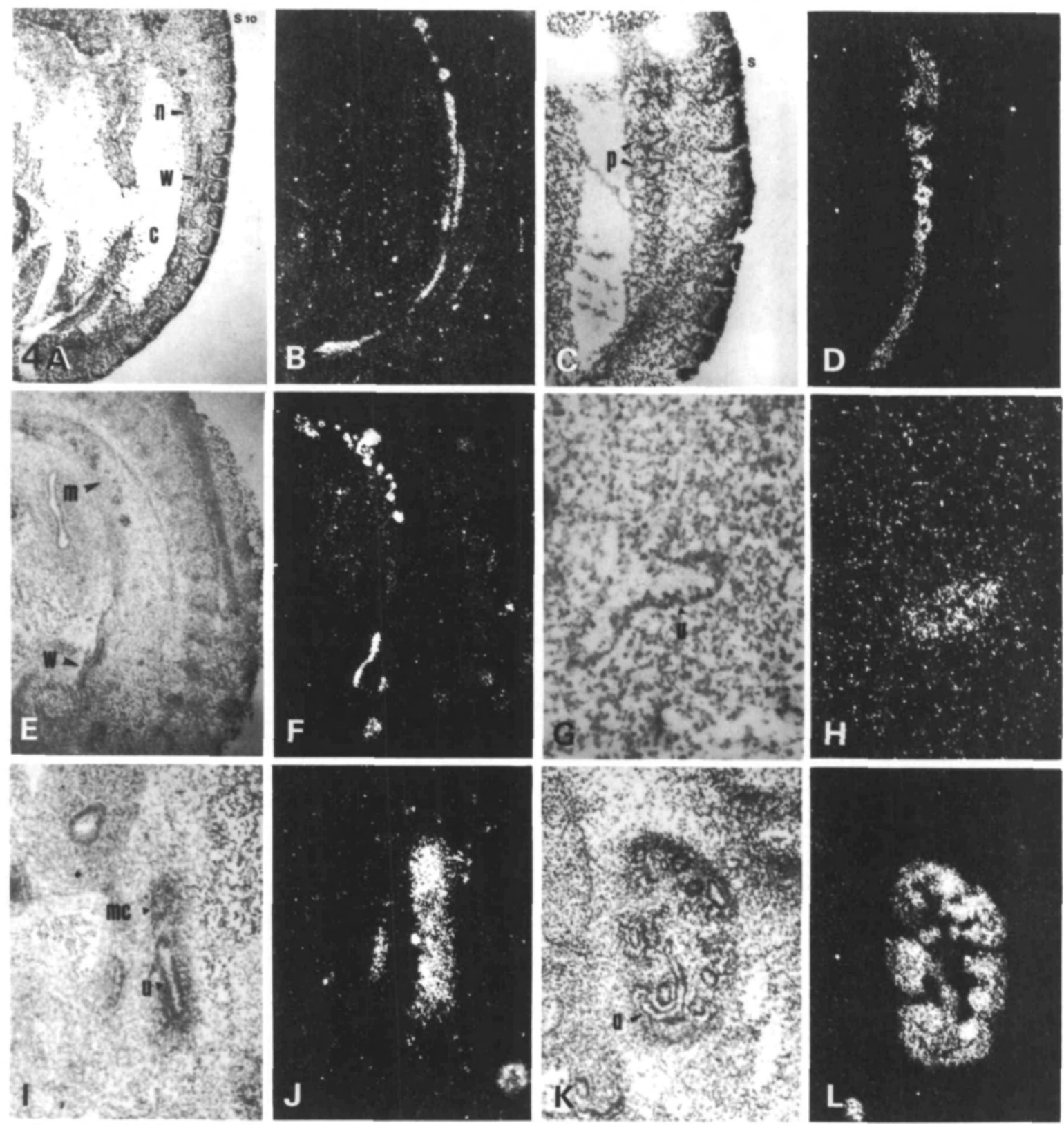

Fig. 4. Early expression of $P a x 2$ in the developing excretory system. (A) Parasagittal section of 10 days p.c. embryo from approximately the 10 th to the 27 th somite. Indicated are the coelom (c), the nephric cord (n) and the Wolffian duct (w), magnification $40 \times$. (B) Dark-field image of A. Note the continuous expression of Pax2 along the anterior-posterior axis. (C) Pronephric tubules (p) at 10 days p.c., magnification 100×. (D) Dark-field image of C. (E) Mesonephros (m) of 11 days p.c. embryo, the Wolffian duct (w) is also indicated, magnification 100x. (F) Dark-field image of E. (G) The ureter (u) budding from the Wolffian duct, magnification $\times 200$. (H) Dark-field image of $G$. (I) Section through the branched ureter from an 11.5 days p.c. embryo showing mesenchymal condensations $(\mathrm{mc})$ around the ureter. (J) Dark-field image of I showing Pax2 expression in the branched ureter and in mesenchymal condensations. (K) Section through the 12 days p.c. metanephros showing the multiply branched ureter (u), which forms collecting ducts, and surrounding mesenchymal condensations. L) Dark-field image of $\mathrm{K}$; again, note the high levels of Pax2 expression in the branched ureter and in mesenchymal aggregates surrounding the ureter.

predominate. This can be a critical substitution (Kozak, 1986) and may inhibit translational initiation. The second and third methionine codons, located 2 and 13 amino acids downstream, respectively, both contain a $\mathrm{G}$ at position -3 , but the remaining flanking sequences deviate more from the proposed consensus. Furthermore, the $5^{\prime}$ leader sequence is extremely GC-rich, approximately $73 \%$; this has been noted for many naturally occurring long 5' leader sequences (Kozak, $1987 b)$. In general, the paired domain is near the $N$-terminus, located $18-30$ amino acids from the terminal methionine for the three Drosophila genes (Frigerio et al. 1986; Baumgartner et al. 1987) and three mouse genes (Deutsch and Gruss; Goulding and Gruss; 

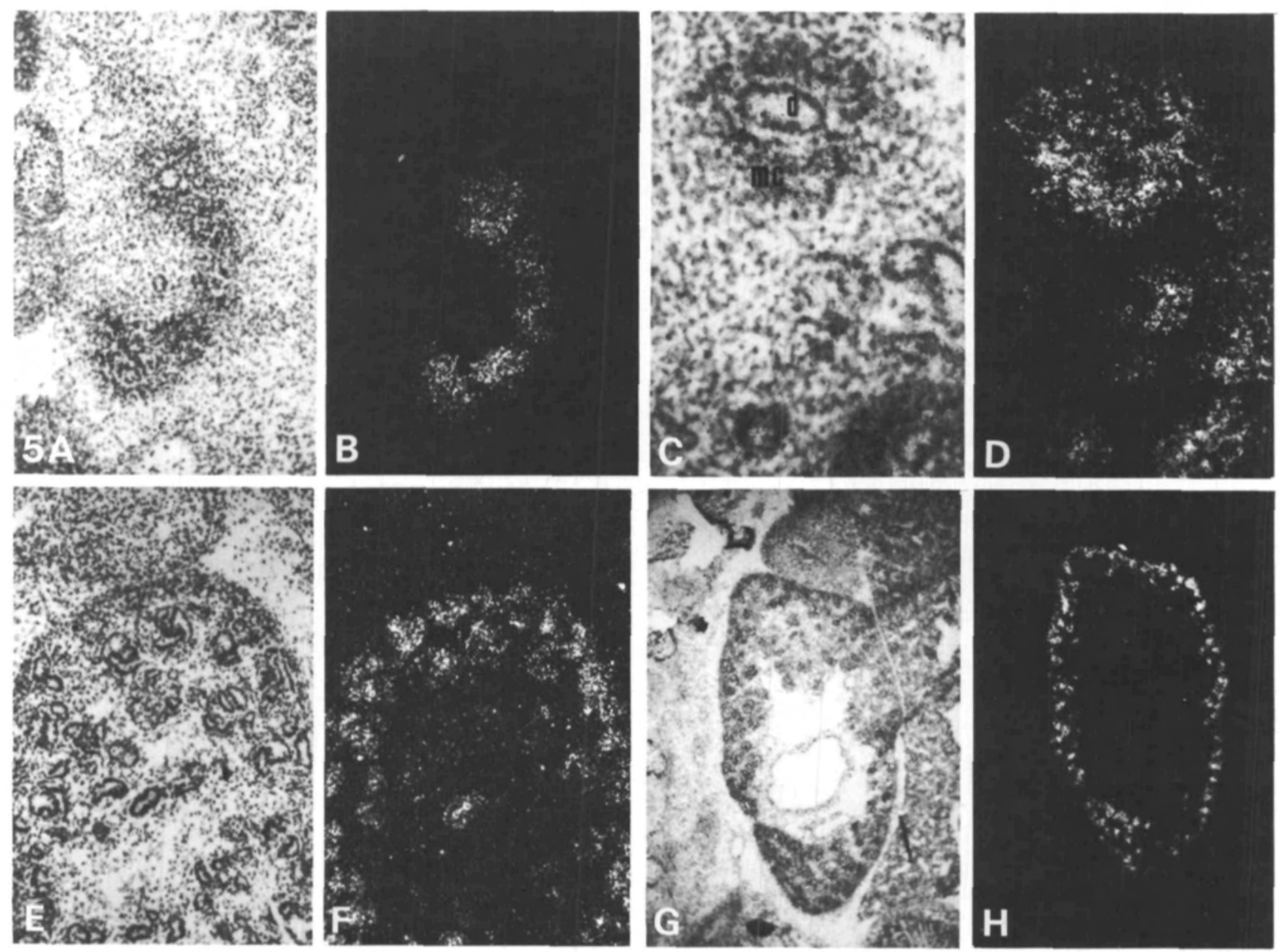

Fig. 5. Late expression of $P a x 2$ in the developing metanephros. (A) Metanephros at 12 days p.c., magnification $\times 100$. (B) Dark-field image of A, note the lack of expression in loose mesenchyme cells. (C) High magnification of 12 days p.c. metanephros showing a transverse section through a collecting duct (c) and surrounding mesenchymal condensations (mc), magnification $\times 200$. (D) Dark-field image of C. Pax2 expression is restricted to collecting ducts and condensed mesenchyme. (E) Metanephros at 14 days p.c., magnification $\times 100$. (F) Dark-field image of E showing Pax2 expression on the perimeter of the growing kidney. (G) Metanephros at 17 days p.c., magnification $\times 40$. (H) Dark-field image of $G$; again, note the absence of Pax 2 expression in the interior of the cortex.

Walther and Gruss, unpublished) sequenced to date. In addition, a new cDNA clone has recently been identified that extends more than $1000 \mathrm{bp}$ downstream of the $3^{\prime}$ end of clone cPX and contains an internal polyadenosine stretch (Dressler, unpublished observation). This would suggest that the Pax 2 mRNA contains a $3^{\prime}$ untranslated sequence of at least $2 \mathrm{~kb}$.

The conservation of the paired domain across divergent species suggests a similarity of biochemical function. In Drosophila, the paired-box-containing genes $p r d, g s b-p$ and $g s b-d$ also contain a paired type homeobox (Frigerio et al. 1986; Baumgartner et al. 1987). However, the homology of $\operatorname{Pax} 2$ to other paired domain proteins is restricted to the paired domain and the paired octapeptide, as Pax 2 does not contain a pairedtype homeobox. Presently, the function of the paired domain is not clear. Computer analysis reveals a potential helix-turn-helix motif in the $C$-terminal end of the paired-box domain. However, there is no direct evidence that this domain has DNA-binding activity or that the Pax genes encode nuclear proteins. A computer search also found some similarity to $c$-fos and c-myc, approximately $21 \%$ identical and $40 \%$ similar. Presently, it is not clear if this similarity is significant. Previously, the Pax2 locus was mapped to mouse chromosome 7 (Dressler et al. 1988); however, fine mapping of the locus is required before any known mutations near Pax 2 can be identified.

The expression of Pax 2 correlates with distinct morphological changes

Although the development of the metanephros is a complex process, individual aspects of induction and cellular interactions have been studied in great detail. At 11 days gestation, development of the kidney begins when the ureteric bud, an outgrowth from the posterior Wolffian duct, meets the metanephric blastema, a loosely organized mesenchymal tissue in the posterior nephric cord. Shortly thereafter, a reciprocal induction event occurs. The ureteric bud is induced to branch and 
the metanephric mesenchyme is induced to form epithelial condensations around the branching ureter. These mesenchymal condensates will eventually form the S-shaped body and subsequently join the collecting duct system. It is not suprising that the ureter expresses the Pax2 gene, since the ureter is an outgrowth of the Wolffian duct. However, it is of interest to note that high levels of Pax 2 transcripts can be detected in the early condensations around the budding ureter, whereas the more loosely organized mesenchyme cells do not appear to express Pax2. Thus, the expression of Pax2 correlates with induction and formation of early metanephric epithelial condensations. At later developmental stages (day 17), Pax2 expression declines in the more developed glomerular crevices but continues to be expressed near the perimeter of the growing kidney. Because the kidney continues to grow after birth, the faint $P a x 2$ hybridization seen with adult kidney RNA may reflect a very low amount of residual transcripts.

The induction of the mesenchymal blastema to form early epithelial condensations requires cell contact with cytoplasmic processes of the inducing tissues (Grobstein, 1957; Saxen and Lehtonen, 1978). Using an in vitro organ culture model, it has been shown that antibodies against the gangliosides $\mathrm{G}_{\mathrm{D} 3}$ (Sariola et al. 1988 ) or the laminin A chain (Klein et al. 1988) disrupt metanephric epithelium formation, indicating that these molecules are involved in the interaction between inducing and responding cells. Changes in gene expression after formation of the early epithelium include the induction of the cell adhesion molecule uvomorulin (Vestweber et al. 1985) as well as the basement membrane glycoprotein laminin (Leivo et al. 1980; Ekblom et al. 1980). Interstitial proteins expressed in the mesenchyme that are not found in metanephric epithelium after induction include collagen type I and III (Ekblom et al. 1981). However, the transduction of signals received at the cell surface and the subsequent regulation of gene expression in responding cells are mechanisms that remain to be characterized. The localization of Pax2 transcripts in inducing ureteric epithelial cells, the subsequent early activation of Pax2 transcripts in responding mesenchyme cells and the transient nature of Pax2 transcript accumulation may indicate that this gene functions in the transduction pathway during cell polarization and/or cell condensation.

In contrast to the $P a x 1$ and $P a x 2$ genes, many murine homeobox (Hox) genes are expressed in a regionspecific, rather than tissue-specific, manner along the rostrocaudal axis (for review see Holland and Hogan, 1988), supporting the concept of positional specification through the combinatorial effect of Hox gene expression. The Pax genes may be involved in more specific aspects of morphogenesis, such as the migration and differentiation of sclerotome subsets during vertebral column development (Paxl) or metanephric mesenchyme condensation and cell polarization ( $P a x 2)$. As discussed in detail in the accompanying report (Nornes et al. 1990), Pax2 is also expressed during neurogenesis in the hindbrain and spinal cord, the otic vesicle and the optic cup. This biphasic expression pattern in mesoderm- and ectoderm-derived tissues may indicate multiple functions of the Pax2 proteins. In fact, many Drosophila segmentation genes have neurogenic functions that are evident later during embryogenesis. Expression of the mouse gene Paxl, however, is limited to segmented mesodermal structures and cannot be detected in nervous tissue. Thus, the neurogenic aspect of Pax gene expression does not appear to be a general principle. In any event, the two Pax genes characterized to date are members of an entirely new gene family whose expression pattern is distinctly different from that of murine homeobox genes and whose function may involve the regulation of specific morphogenetic events.

We thank Sabine Geisendorf for expert technical assistance, D. Plachov for rescreening, H. Jäckle and S. Côté for the Drosophila gooseberry clones, A. Joyner and G. Martin for the cDNA library and R. Altschaffel for excellent photography. G. R. D. is a recipient of an Alexander von Humboldt fellowship.

\section{References}

Aкам, M. (1987). The molecular basis for metameric pattern in the Drosophila embryo. Development 101, 1-22.

Balling, R., Deutsch, U. and Gruss, P. (1988). undulated, a mutation affecting the development of the mouse skeleton, has a point mutation in the paired box of Paxl. Cell 55, 531-535.

Baumgartner, S., Bopp, D., Burri, M. and Noll, M. (1987). Structure of two genes at the gooseberry locus related to the paired gene and their spatial expression during embryogenesis. Genes and Dev. 1, 1247-1267.

Bopp, D., Burri, M., Baumgartner, S., Frigerio, G. and Noll, M. (1986). Conservation of a large proten domain in the segmentation gene paired and in functionally related genes of Drosophila. Cell 47, 1033-1040.

Breier, G., Dressler, G. R. And Gruss, P. (1988). Primary structure and developmental expression pattern of Hox 3.1, a member of the murine Hox 3 homeobox gene cluster. EMBO J. 7, 1329-1336.

Burri, M., Tromvoukis, Y., Bopp, D., Frigerio, G. and Noll, M (1989). Conservation of the paired domain in metazoans and its structure in three isolated human genes. EMBO J. 8, 1183-1190.

Chirgwin, J. M., Przybyla, A. E., MacDonald, R. J. and RUTTER, W. J. (1979). Isolation of biologicaly active ribonucleic acid from sources enriched in ribonucleases. Biochemistry 18 , 5294-5299.

Deutsch, U., Dressler, G. R. And Gruss, P. (1988). Paxl, a member of a paired box homologous murine gene family, is expressed in segmented structures during development. Cell 53, 617-625.

Devereux, J., Haeberli, P. and Smithies, O. (1984). A comparison set of sequence analysis programs for the VAX. Nucl. Acid Res. 12, 387-395.

Dony, C. AND Gruss, P. (1987). Specific expression of the Hox 1.3 homeo box gene in murine structures originating from or induced by the mesoderm. EMBO J. 6, 2965-2975.

Dressler, G. and Gruss, P. (1988). Do multigene families regulate vertebrate development? Trends Genet. 4, 214-219.

Dressler, G. R., Deutsch, U., Balling, R., Simon, D., Guenet, J. L. AND Gruss, P. (1988). Murine genes with homology to Drosophila segmentation genes. Development 104 suppl. 181-186.

Ekblom, P., Altralo, K., Vaheri, A., Timpl, R. and Saxen, L. (1980). Induction of a basement membrane glycoprotein in embryonic kidney: possible role of laminin in morphogenesis. Proc. nam. Acad. Sci. U.S.A. 77, 485-489.

Ekblom, P., Lehtonen, E., Saxen, L. and Timpl, R. (1981). Shift 
in collagen types as an early response to induction of the metanephric mesenchyme. J. Cell Biol. 89, 276-283.

Fahrner, K., Hogan, B. L. M. and Flavell, R. A. (1987). Transcription of $\mathrm{H}-2$ and $\mathrm{Q} a$ genes in embryonic and adult mice. EMBO J. 6, 1265-1271.

Feinbera, A. P. And Vogelstein, B. (1983). A technique for radiolabeling DNA restriction endonuclease fragments to high specific activity. Anal. Biochem. 132, 6-13.

Fitzoerald, M. and Shenk, T. (1981). The sequence 5'-

AAUAAA $-3^{\prime}$ forms part of the recognition site for polyadenylation of late SV40 mRNAs. Cell 24, 251-260.

Frigerio, G., Burri, M., Bopp, D., Baumgartner, S. ANd Noll, M. (1986). Structure of the segmentation gene paired and the Drosophila PRD gene set as part of a gene network. Cell 47, 735-746.

Grobstein, C. (1957). Some transmission charateristics of the tubule-inducing influence on mouse metanephrogenic mesenchyme. Expl Cell Res. 13, 575-587.

GrUNererG, H. (1954). Genetical studies on the skeleton of the mouse. XII. The development of undulated. J. Genet. 52, 441-455.

Hogan, B., Constantini, F. and Lacy, E. (1986). Manipulating the Mouse Embryo: A Laboratory Manual, Cold Spring Harbor Press, pp228-235.

Holland, P. W. H. and Hogan, B. L. M. (1988). Expression of homeo box genes during mouse development: a review. Genes \& Dev. 2, 773-782.

Ingham, P., Howard, K. ANd Ish-Horowitz, D. (1985).

Transcription pattern of the Drosophila segmentation gene hairy. Nature 318, 439-445.

InGHAM, P. W. (1988). The molecular genetics of embryonic pattern formation in Drosophila. Nature 335, 25-34.

Joyner, A. L. AND MArtin, G. R. (1987). En-l and En-2, two mouse genes with sequence homology to the Drosophila engrailed gene: expression during embryogenesis. Genes \& Dev. 1, 29-38.

Klein, G., langegger, M., Timpl, R. and Ekblom, P. (1988). Role of laminin A chain in the development of epithelial cell polarity. Cell 55, 331-341.

KozaK, M. (1986). Point mutations define a sequence flanking AUG initiator codons that modulates translation by eukaryotic ribosomes. Cell 44, 283-292.

KozAK, M. (1987a). At least six nucleotides preceding the AUG initiator codon enhance translation in mammalian cells. J. molec. Biol. 196, 947-950.

KozAK, M. (1987b). An analysis of $5^{\prime}$-noncoding sequences from 699 vertebrate messenger RNAs. Nuc. Acids Res. 15, 8125-8146.

Leivo, I., Vaheri, A., Timpl, R. and Wartiovaara, J. (1980).
Appearance and distribution of collagens and laminin in the early mouse embryo. Devl Biol. 76, 100-114.

Leon, J., Guerrero, I. And Pellicer, A. (1987). Differential expression of the ras gene family in mice. Mol. Cell. Biol. 7 , $1535-1540$.

MaXam, A. M. AND Gilbert, W. (1980). Sequencing end labeled DNA with base specific chemical cleavages. Meth. Enzymol. 65, 499-560.

Nornes, H. O., Dressler, G. R., Knapik, E. W., Deutsch, U. AND Gruss, P. (1990). Spatially and temporally restricted expression of Pax2 during murine neurogenesis. Development 109, 797-809.

Proudfoot, N. ANd Brownlee, G. G. (1976). 3' non-coding region sequences in eukaryotic messenger RNA. Nature 263, 211-214.

SANGer, F, Nicklen, S. ANd Coulson, A. R. (1977). DNA sequencing with chain termination inhibitors. Proc. natn. Acad. Sci. U.S.A. 74, 5463-5467.

Sariola, H., Aufderheide, E., Bernhard, H., Henke-Fahle, S., DipPold, W. AND EKrlom, P. (1988). Antibodies to cell surface ganglioside $G_{D 3}$ perturb inductive epithelial-mesenchymal interactions. Cell 54, 235-245.

SAXEN, L. (1987). Organogenesis of the Kidney, Developmental and Cell Biology Series 19 (ed. P. W. Barlow, P. B. Green and C. C. White) Cambridge Univ. Press.

SaXen, L. AND Lehtonen, E. (1978). Transfilter induction of kidney tubules as a function of the extent and duration of intercellular contacts. J. Embryol. exp. Morph. 47, 97-109.

ScotT, M. P. ANd Carroll, S. B. (1987). The segmentation and homeotic gene network in early Drosophila development. Cell 51, 689-698.

Stanton, L. W., Fahrlander, P. D., Tesser, P. M. and Marcu, K. B. (1984). Nucleotide sequence comparison of normal and translocated murine c-myc genes. Nature 310, 423-425.

van Straaten, F., Müller, R., Curran, T., van Beveren, C. and Verma, I. M. (1983). Complete nucleotide sequence of a human c-onc gene: Deduced amino acid sequence of the human $c$-fos protein. Proc. natn. Acad. Sci. U.S.A. 80, 3183-3187.

Vestweber, D., Kemmler, R. and Ekblom, P. (1985). Cell adhesion molecule uvomorulin during kidney development. Devl Biol. 112, 213-221.

Wright, C. V. E., Cho, K. W. Y., Oliver, G. And De Robertis, E. M. (1989). Vertebrate homeodomain proteins: families of region-specific transcription factors. TIBS 14, 52-56. 